\title{
A methodology to calculate long-term shallow geothermal energy potential for an urban neighbourhood
}

\author{
Journal Article \\ Author(s): \\ Miglani, Somil; Orehounig, Kristina; Carmeliet, Jan \\ Publication date: \\ 2018-01-15 \\ Permanent link: \\ https://doi.org/10.3929/ethz-b-000217121
}

Rights / license:

In Copyright - Non-Commercial Use Permitted

Originally published in:

Energy and Buildings 159, https://doi.org/10.1016/j.enbuild.2017.10.100 


\section{A methodology to calculate long-term shallow geothermal energy potential for an urban}

5 b Urban Energy Systems Laboratory, Swiss Federal Laboratories for Materials Science and Technology, EMPA, Duebendorf, 6 Switzerland

7 *Corresponding author address: Stefano Franscini Platz 1, ETH Hoengerberg, CH 8093. Tel: +41 789290340

\section{Abstract}

9 Ground source heat pumps typically use Borehole Heat Exchangers (BHEs) which are drilled vertically into the ground to extract 10 heat. Space limitations in urban areas can limit the total length of BHEs. Continuous heat extraction over long period from BHEs 11 especially with limited length results in cooling of the ground. Furthermore, the presence of neighbouring BHEs adds to the cooling 12 effect thereby reducing the overall geothermal energy potential. Therefore, it is important to consider spatial constraints and the 13 thermal interference from neighbouring BHEs when evaluating the geothermal energy potential of urban areas. In this paper, a 14 methodology to calculate the long-term geothermal energy potential for an urban neighbourhood is developed. A GIS based 15 workflow is used to design the BHEs for multiple buildings, in order to satisfy their total heating/cooling demand considering 16 spatial constraints. A model that accounts for thermal interference between neighbouring BHEs is developed to simulate their 17 operation and the long-term geothermal energy potential is calculated. The method is applied to an urban neighbourhood in Zurich, 18 Switzerland with 170 buildings. Results show that the geothermal energy potential is overestimated if thermal interference between 19 BHEs are not accounted for. A long-term declining trend is observed in the geothermal energy potential due to ground cooling.

20 Keywords: Building energy demand, Borehole heat exchanger, Shallow geothermal energy, GIS, Renewable energy

\section{1. Introduction}

\subsection{Background}

23 Human induced climate change, depleting fossil fuel reserves and the increasing pressure from the global populace for cleaner 24 sources of energy, are pushing the energy sector towards a transition. The seeds of this transition have been sowed through the 25 development of energy strategies by the world's major economies. For instance, the European Union (EU) is committed to reducing 26 its collective GHG emissions by 20\% from the 1990 levels by 2020 [1] and 80-95\% by 2050 [2]. These targets are ambitious and 27 necessitate an energy system with an exceptionally high share of renewable energy. Furthermore, contributions are needed from 28 various energy consuming sectors such as buildings, transport, industry, agriculture etc. The building sector in the EU represents $2940 \%$ of the total final energy use [3] and contributes $36 \%$ of $\mathrm{CO}_{2}$ emissions [4] providing an opportunity to reduce a substantial 30 amount of emissions. The Energy Performance of Buildings Directive, which is the main legislation in the EU for energy efficient 31 buildings also advocates the use of heat pumps and renewable energy for heating and cooling in buildings [5]. Furthermore, the 
32 International Energy Agency (IEA) also recommends the installation of heat pumps for space heating, cooling and domestic hot 33 water (DHW) as an immediate priority [3].

34 Ground Source Heat Pumps (GSHPs) are a mature technology that has been widely used in buildings for space heating/cooling 35 and DHW production. Recent advances have led to the increase in the energy efficiency of these systems making them an attractive 36 alternative for heating in buildings [6]. In terms of $\mathrm{CO}_{2}$ emissions and energy efficiency, GSHPs rank higher than all fossil fuel 37 based boilers and their air source counterparts [7]. A GSHP uses the ground, ground water or surface water as its source or sink. 38 There are two main types of GSHP systems, the closed loop system and the open loop system. In a closed loop system the GSHP 39 is connected to a U-pipe heat exchanger installed underground through which a water or water-antifreeze mixture is circulated to 40 exchange heat with the ground. Borehole Heat Exchangers (BHE) which are drilled vertically into the ground are a commonly 41 used example of such a system. An open loop system draws water directly from the water table or a lake, pond etc. and passes it 42 through the heat pump. There are several other types and configurations of heat exchangers that are used in conjunction with the 43 heat pump, which differ in their design, costs, spatial constraints, installation requirements etc. A detailed description of the 44 different heat exchangers used with GSHPs is described by Florides and Kalogirou [8].

45 BHEs are ideal for urban areas where surface area is limited and the desire for interference with the landscape is minimal. BHEs 46 can be drilled in the space between the building walls and the parcel boundary. The primary design parameter for each BHE is its 47 total length that determines the possible heat extraction from the ground. The longer the BHE length the higher the possible heat 48 extraction. Contrastingly, the drilling costs increase with every meter drilled. Therefore, a good design of the BHE system should 49 size for the minimum length that is required for satisfying the total thermal energy demand. For high heating and cooling demands, 50 there may be a need for installation of multiple BHEs to achieve long lengths connected to a single heat pump supplying heat to a 51 building. In that case, the separation distance between BHEs is critical in order to minimize the thermal interference between them. 52 Although a large separation distance reduces the thermal interference, it also restricts the number of BHEs that can be installed 53 within a given area, reducing the total length. Besides the separation distance, the BHEs must be distanced from the parcel 54 boundaries shared with neighbouring parcels. This ensures fair use of the ground volume and minimal interference from the 55 neighbouring systems. Dense urban areas are usually limited in space for installation of such systems. Furthermore, there are 56 drilling restrictions usually linked to the protection of deep aquifers and presence of infrastructure such as tunnels, networks etc. $57[11,9]$. In Switzerland there are guidelines for the protection of ground water resources which prescribe a spatially varying 58 maximum allowed drilling depth [12]. The above-discussed spatial constraints can greatly limit the total length that can be drilled 59 thereby under sizing the BHEs. Therefore, a spatial modelling approach can greatly enhance the design process for installation of 60 BHEs in urban areas. Other factors affecting heat extraction such as the spatially varying soil type can also be easily incorporated 61 into the spatial modelling approach. 
62 Assume an urban area consists of multiple buildings installed with BHEs extracting heat from the ground at the same time. Since

63 the BHEs are using the same ground resource, the heat extraction of a single BHE is affected by the heat extraction of the 64 neighbouring BHEs. Simultaneously operating BHEs in an area can cause excessive heat extraction, especially when they are 65 under sized. Excessive heat extraction causes undesirably low temperatures in the BHE that can damage the filling material. In the 66 worst case scenario the circulating fluid can leak and mix with the otherwise separate ground water [6, p. 28]. To prevent this, the 67 Swiss standard for design of BHEs prescribes a minimum threshold value of $-1.5^{\circ} \mathrm{C}$ for the mean fluid temperature (MFT) in the 68 BHE [14]. During operation, when the MFT drops below the given threshold, an auxiliary heating device is necessary to fulfil the 69 remaining unmet heating demand of the building, until the BHE recovers naturally using the heat influx from the far ground. The 70 heat demand that is met by the BHE maintaining the MFT above the given threshold is termed as geothermal energy potential 71 (GEP). The MFT not only depends on the short-term heat extraction from the ground but also the long-term heat extraction.

72 Therefore, long-term operation of the BHEs can result in declining trends in the MFT over the BHEs' lifetime thereby reducing 73 the GEP.

74 The above discussion highlights that the calculation of the GEP for an urban area consists of spatial as well as temporal 75 considerations. Spatial restrictions such as parcel size, drilling depth can limit the design of BHEs that in turn can affect their 76 operational performance. The operation of such systems over longer periods can lead to the cooling of the ground lowering the net 77 available GEP. Emphasis must be laid on incorporating these factors into the modelling process when assessing GEP.

\subsection{Previous work}

79 Previous research suggests that there has been an increased interest in the assessment of shallow geothermal energy potential 80 in recent years. GIS has predominantly been used to support the different methodologies proposed by several studies on this topic.

81 The methods vary from simulation [15], analytical [9,16-18]and empirical models[15,19] to assess the GEP at relatively smaller 82 city scales $[9,20,21]$ as well as larger regional scales [16-18]. The purpose of these studies varies from large scale mapping $83[18,19,21]$, techno-economic decision support [16,22], $\mathrm{CO}_{2}$ emissions mitigation $[9,23]$, to building specific applications $[9,20]$.

84 The approach by Galgaro et al. [15] employs multiple runs of a simulation model EED [24] to generate an empirical model for a 85 BHE, to be applied to a large scale case study. They use a highly detailed description of the three-dimensional space around the 86 BHE in terms of the ground thermal properties like thermal conductivity, diffusivity and ground temperature. The aim of this study 87 is to generate large-scale geothermal potential maps; therefore, the detailed treatment of the BHEs, their thermal interference with 88 each other and the specific building characteristics such as construction age, thermal insulation, heated area, occupants etc. are 89 omitted.

90 Schiel et al. [9] use a specific heat extraction ( $\left.\mathrm{sHE}, \mathrm{Wm}^{-1}\right)$ method in conjunction with a GIS based workflow to assess the shallow 91 geothermal potential through the use of BHEs and its effects on $\mathrm{CO}_{2}$ emissions mitigation for the city of Ludwigsburg, Germany. 
92 This method uses the standard sHE values for each soil type which when multiplied by the total BHE length, results in the GEP.

93 In their approach, they capture the specific building energy characteristics through energy demand calculations and spatially fitting

94 BHEs within the parcel boundaries for each building. This building level detail is also accounted for by Zhang et al. [20] who

95 focus on the heat pumps connected to BHEs by calculating their electricity usage and costs. They use measured COP values of

96 GSHPs for each building. The sHE method is used in other studies such as Munoz et al. [18] to calculate the shallow geothermal

97 potential for the large Santiago basin in Chile. They focus on BHEs as well as ground water heat exchangers (GWHEs) with depth

98 ranging from 10-400m. Other studies for other large scale regions such as the Italian Marche [16] and south-west Germany [17]

99 also use the sHE method for economic and technical feasibility analysis respectively. The mathematical simplicity of the sHE 100 method and its easy integration within GIS workflows makes it favourable for the large-scale mapping of shallow geothermal 101 potential. However, this method is incapable of accounting for spatial aspects such as thermal interference between BHEs and 102 temporal aspects such as long-term operation, both of which affect the GEP.

103 Casasso and Sethi $[16,21]$ fill this gap by addressing the sustainable heat extraction from the BHEs over time. They follow a 104 bottom up approach, by developing a method named G.POT that calculates the maximum possible heat extraction from each BHE 105 by restricting the fluid temperature within the BHE to $-2{ }^{\circ} \mathrm{C}$. However, this method assumes that the BHEs respond to a single 106 sinusoidal heat demand profile; hence, omitting the building specific details of the thermal energy demand. The method is fast and 107 suitable for the application for large-scale mapping of the shallow geothermal potential. However, it does not address the thermal 108 interference between BHEs that may affect their performance limiting the total geothermal potential.

109 A majority of the studies in the literature focus on large-scale mapping of the GEP and therefore rely on using computationally 110 efficient methods. As a result, the bottom up modelling of the BHE systems is often not taken into consideration. The models in 111 literature do not address the thermal interference between BHEs, long-term operational limits and their effects on the net available 112 GEP. Although the specific characteristics that differentiate between buildings are considered in some studies, this aspect can be 113 improved further by using state of the art building energy simulation tools.

\subsection{This work}

115 The main aim of this work is the development of a methodology to estimate the long-term GEP of an urban area focussing 116 on (1) spatial constraints on the design of BHEs, (2) thermal interference between neighbouring BHEs (3) long-term operation of 117 the BHEs and (4) accurate calculation of building energy demand. A GIS based workflow is developed to position and size the 118 BHEs in an urban area taking into account drilling depth restrictions and space limitations within parcels. The methodology 119 developed in this work considers the thermal interference of BHEs between each other. The long-term operation of the BHEs is 120 simulated using an analytical model and its impact on the available GEP is studied. The methodology is applied to an urban 121 neighbourhood as a case study in Switzerland. The spatial approach followed in the study can help in the planning process of large- 
122 scale installations of BHEs in urban areas. The inclusion of the thermal interference between BHEs and their long-term operation 123 into the modelling process provides a more accurate assessment of the GEP. The paper is organised as follows; section 2 describes 124 the input data and developed methodology, section 3 describes the case study and its input parameters, in section 4 the main results 125 are discussed followed by section 5 that concludes this study.

\section{2. Methodology}

127 The methodology developed in this study consists of three major steps: (1) calculation of thermal energy demand, (2) sizing 128 of BHEs and (3) operation of BHEs. Furthermore, to study the effects of thermal interference between BHEs on the overall GEP 129 a comparative analysis is made with a reference case that assumes no thermal interference between BHEs. The entire workflow 130 has been outlined in Figure 1.

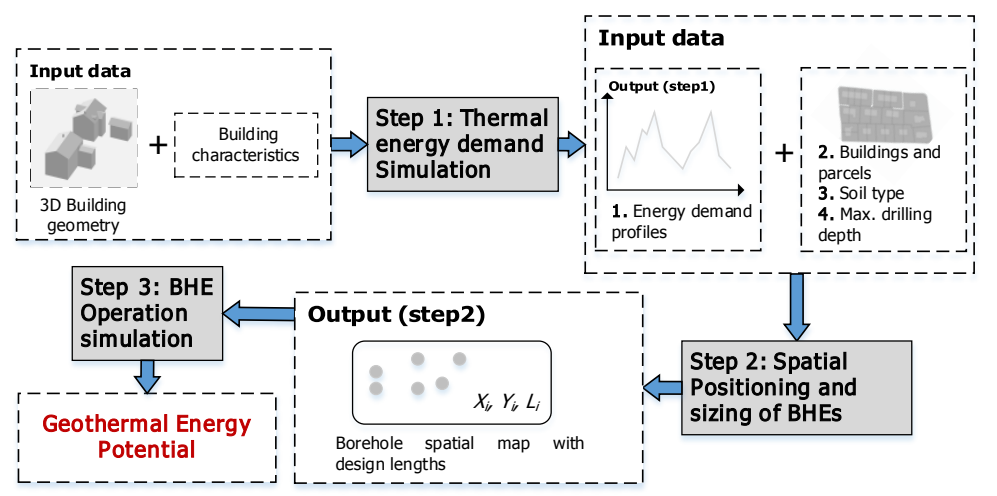

133 In a first step, total thermal energy demand for each building under consideration is calculated. Building specific characteristics 134 such as age, thermal insulation, occupancy, glazing ratio and number of floors are taken into account. To simulate the operation 135 of the BHEs an hourly thermal energy demand profile is necessary, therefore a dynamic building energy simulation is used as 136 described in section 2.2 .

137 Secondly, the BHEs are designed for each building parcel, which includes first, the spatial positioning of BHEs within the 138 building's parcel and second, sizing the BHEs for their total length to satisfy the given thermal energy demand. A GIS based 139 workflow is used as described in section 2.3.

140 Thirdly, an analytical model accounting for the thermal interference between BHEs is used to simulate the long-term operation of 141 the BHEs. Hourly thermal energy demand is used as input for the simulation. The time varying MFT is obtained and is used to 142 calculate the unmet heat demand. This is described in section 2.4 .

143 As a result, the long-term annual potential of geothermal energy is calculated through aggregation of the met heating demand as 144 described in section 4.6 .

145 Subsequently, a comparative analysis is performed to emphasize the impact of thermal interference between BHEs. The results of 146 this study are compared with a reference case that assumes no thermal interference between BHEs as described in section 4.5. 


\section{2.1 Input Data}

148 The main input data used for building energy simulation are the 3D building geometry, weather data and building specific 149 characteristics. GIS data on building footprints, parcel boundaries, soil type and drilling restrictions (Figure 2) is used in the 150 modelling of the GEP. A list of the main input data used along with their source and technical specifications are summarized in 151 table 1.

152 Table 1: Input data: description, technical information and source

\begin{tabular}{llll}
\hline Dataset & Format & Description & Source \\
\hline Building Geometry & $\begin{array}{l}\text { CAD } \\
\text { dxf file format }\end{array}$ & 3D CAD model of each building & Swisstopo [26] \\
\hline Building characteristics & $\begin{array}{l}\text { Points } \\
\text { (Esri Shapefile) }\end{array}$ & $\begin{array}{l}\text { Building characteristics such as, age, number of } \\
\text { floors, occupants. Each building is represented } \\
\text { by a point. }\end{array}$ & Bundesamt für Statistik [27] \\
\hline Weather data & $\begin{array}{l}\text { Energy Plus } \\
\text { epw file format }\end{array}$ & $\begin{array}{l}\text { Energy plus weather file interpolated using } \\
\text { Meteonorm [28] }\end{array}$ & Meteonorm [28] \\
\hline Building footprints & $\begin{array}{l}\text { Polygon } \\
\text { (ESRI Shapefile) }\end{array}$ & $\begin{array}{l}\text { The building footprints from the municipality } \\
\text { cadastre data as a polygon vector file. }\end{array}$ & $\begin{array}{l}\text { Amt für Raumentwicklung } \\
\text { (ARE) [29]. }\end{array}$ \\
\hline Parcel boundaries & $\begin{array}{l}\text { Polygon } \\
\text { (ESRI Shapefile) }\end{array}$ & $\begin{array}{l}\text { The parcel boundaries from the municipality } \\
\text { cadastre data as a polygon vector file. }\end{array}$ & ARE [29] \\
\hline Soil type & $\begin{array}{l}\text { Polygon } \\
\text { (ESRI Shapefile) }\end{array}$ & $\begin{array}{l}\text { The spatial distribution of soil type as a polygon } \\
\text { vector file. The thermal properties for each soil } \\
\text { type are derived from [14] }\end{array}$ & Federal Office of the \\
& Environment [30] \\
\hline Maximum drilling depth & Raster & $\begin{array}{l}\text { The maximum allowed drilling depth as a raster } \\
\text { with a 5m resolution (Figure 2). This dataset is } \\
\text { based on the water protection law [12] }\end{array}$ & ARE [31] \\
\hline
\end{tabular}

\section{2.2 Thermal energy demand simulation}

154 The thermal energy demand of each building consisting of space heating, cooling and DHW is calculated on an hourly basis 155 using an approach developed by Wang et al. [32]. The input data used for this calculation are the building geometry in the form of 156 a 3D CAD model, the building specific characteristics including building age, glazing ratio, number of floors, occupants and the 157 local weather conditions in the form of a typical meteorological year (TMY) weather file. This approach uses Energy Plus [33], a 158 dynamic building energy simulation program that accounts for occupancy schedules, thermostat settings, infiltration rates etc. for 159 each building separately. The 3D geometry of each building is used to calculate thermal zones within the building as well as 160 shading effects from the surrounding buildings that influences the solar gains. As a result, hourly profiles for space heating, cooling 161 and DHW demand for each building are obtained for the whole year. Since the building is coupled to the BHE through a heat 162 pump, a constant COP of 4.0 and EER of 4.5 is assumed for the heat pump to calculate the ground loads. In practice, the COP and 163 EER varies with BHE temperature, load side delivery temperature, load/source side mass flow rates etc. Since the heat pump is 164 not central to this study constant values have been assumed.

\section{2.3 Design of BHEs}

166 The design of BHEs is divided into two parts, first, the spatial positioning of BHEs within the building parcel and second, 167 the sizing of the BHEs to satisfy the given heat demand. 


\section{2.3.1 Spatial positioning of BHEs}

169 A GIS based workflow is developed to calculate the area eligible for the installation of BHEs for each building parcel. The 170 placement of the BHEs within the parcel must obey spatial constraints including, a minimum separation distance of $5 \mathrm{~m}$ between 171 BHEs as prescribed by the Swiss standard for design of BHEs [14]. A conservative value of $7.5 \mathrm{~m}$ is chosen for this study to 172 minimise thermal interference between BHEs as compared to the case with separation distance of $5 \mathrm{~m}$. A safety margin of $3 \mathrm{~m}$ is 173 maintained inwards from the parcel boundary and outwards from the building wall where no BHEs can be installed. This margin 174 is subtracted from the total parcel area to get the eligible area. Figure 3 demonstrates the eligible area for a selection of example 175 buildings. In the next step, a regular matrix of points, each representing a BHE, is fit into the eligible area polygon obtained in the 176 previous step. Finally, GIS data on maximum allowed drilling depth and local soil type is extracted for each point from the data 177 layers described in Table 1 and added as attributes. A spatial map of BHEs each represented by a point with fixed coordinates 178 having soil type and drilling depth as attributes is obtained.

179

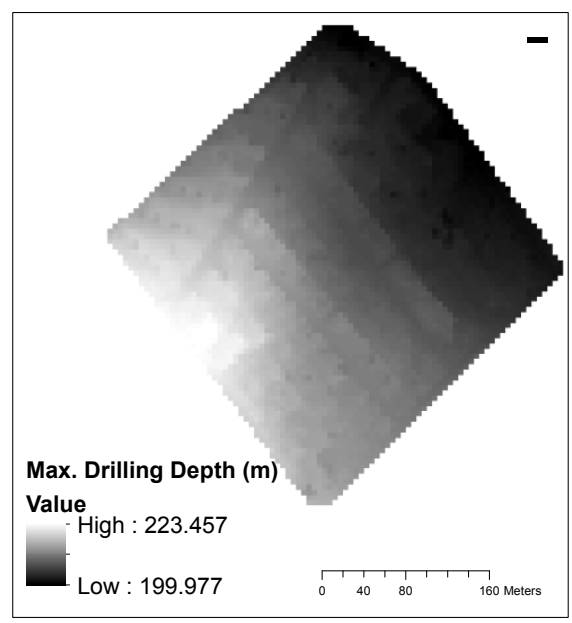

Figure 2: Maximum drilling depth (in $\mathrm{m}$ ) raster for the case study

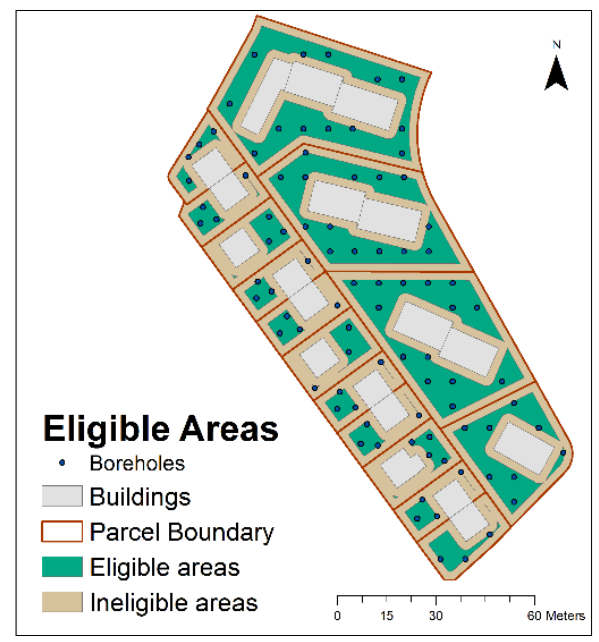

Figure 3: Eligible area around buildings for installation of BHEs

\section{2.3.2 Sizing the BHE length}

181 The ASHRAE method [34], further simplified by Bernier [35] is used for calculating the design length of the BHEs and the 182 main equation used for this calculation is given by (1). Calculations are performed only for the heating cycle, as it is the 183 predominant mode of operation for the case study described in section 3 .

$$
L_{h}=\frac{q_{h} R_{b}+q_{y} R_{10 y}+q_{m} R_{1 m}+q_{h} R_{6 h}}{T_{m f}-\left(T_{g r, \infty}+T_{p}\right)}
$$

185 Where $L_{h}$ is the BHE design length for the heating cycle. $q_{h}, q_{y}, q_{m}$ are respectively the peak hourly, yearly average and peak 186 monthly ground loads in W. $R_{b}, R_{10 y}, R_{1 m}$ and $R_{6 h}$ are respectively the borehole thermal resistance, effective ground thermal 187 resistances for a 10 yearly, monthly and 6 hourly pulse in $\mathrm{mK} / \mathrm{W} . T_{m f}, T_{g r, \infty}$ and $T_{p}$ are respectively the MFT in the BHE u-pipe, 
188 the undisturbed ground temperature and the temperature penalty in K. The detailed calculation methods for effective thermal 189 resistances of the ground for different thermal pulses are described by Kavanaugh \& Rafferty [34].

$190 T_{p}$, the temperature penalty represents the average ground cooling at the end of the lifetime of the BHE, allowing including the 191 effects of ground cooling into the design process. To estimate $T_{p}$ a method prescribed by ASHRAE is used [34]. This method is 192 based on the calculation of the ground volume around a BHE in which the annual heat imbalance is stored. If there is an annual 193 net heat extraction, the temperature of this volume decreases and vice versa. An energy balance assuming steady state is used to 194 calculate this change in temperature of the given volume at the end of the BHE's lifetime. In the next step, an iterative procedure 195 is followed which updates the temperature penalty after each calculation of the length until it converges and results in the final 196 design length.

\section{2.4 BHE operation simulation}

198 Once the design of the BHEs is successfully achieved and their spatial positions and lengths are fixed, the operation of the 199 BHEs is simulated using a mathematical model. This simulation is performed for each BHE on an hourly basis for 10 years. A 200 value of 10 years is chosen to keep the simulation computationally tractable. First, the borehole map consisting of $X_{i}, Y_{i}$ coordinates 201 and lengths $\left(L_{i}\right)$ obtained from the design process are used as input to calculate the thermal response factors (g-functions, see 202 section 2.4.1). Temporal superposition is applied to all the BHEs using their g-functions and heat demands to obtain their respective 203 temperature responses (see section 2.4.2). Spatial superposition is applied to calculate the BHE wall temperature accounting for 204 thermal interference from neighbouring BHEs. Subsequently, a steady state heat transfer equation is used to calculate the time 205 varying MFT. The different parts of the workflow used for the mathematical modelling of the operation are described in the 206 following sections and summarized in Figure 4.

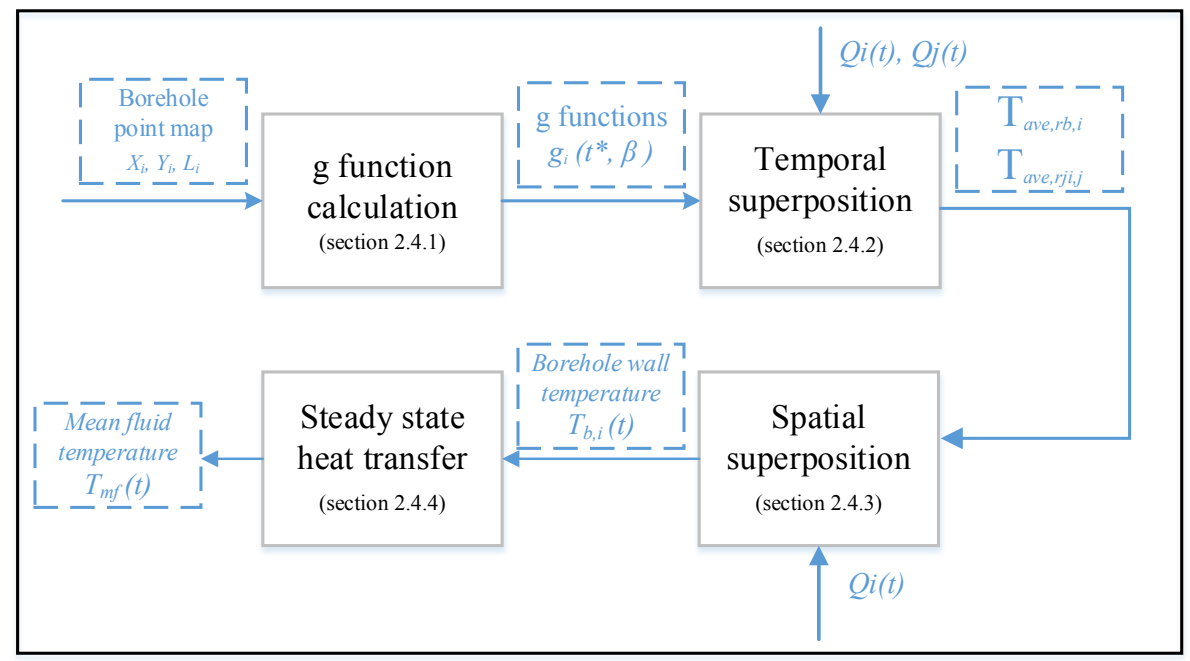

Figure 4: Workflow describing the modelling of the BHE operation simulation 


\section{2.4.1 BHE Thermal response}

\section{0 g-functions}

211 g-functions also called as dimensionless temperature response factors were first described and defined in Eskilson's $\mathrm{PhD}$ 212 thesis [36]. They enable the quantification of the average temperature over BHE length at any radius around a BHE, in response 213 to a step heat pulse. The g-functions are calculated as the solution to the finite line source (FLS) model [37] of the BHEs. A 214 numerically efficient analytical expression given by (2) developed by Lamarche \& Beauchamp [38] for the FLS solution is 215 employed to calculate the g-function for each BHE.

$$
g\left(t^{*}, \beta\right)=\int_{\beta}^{\sqrt{\beta^{2}+1}} \frac{\operatorname{erfc} c(\gamma z)}{\sqrt{z^{2}-\beta^{2}}} d z-D_{A}-\int \frac{\sqrt{\beta^{2}+4}}{\sqrt{\beta^{2}+1}} \frac{\operatorname{rfc} c(\gamma z)}{\sqrt{z^{2}-\beta^{2}}} d z-D_{B}
$$

$$
\beta=\frac{r}{L} ; \quad t^{*}=\frac{t}{t_{s}} ; \quad t_{s}=\frac{L^{2}}{9 \alpha}
$$

218 Where $r$ is the radial distance from the BHE center; $L$ is the BHE length; $t$ is the time and $\alpha$ is the thermal diffusivity of the ground 219 surrounding the BHE. $D_{A}$ and $D_{B}$ are functions dependent on time and BHE length the detailed definition of which can be found 220 in [38].

\section{Temperature response}

222 According to the definition of g-functions, (3) is used to obtain the actual temperature response from its non-dimensional 223 form. The actual temperature response i.e. the average temperature at given radius from the BHE centre is dependent on the thermal 224 properties of the ground surrounding the BHE, its length and the step heat pulse applied to the ground.

$$
T_{\text {ave }, r}-T_{g r, \infty}=\frac{Q}{2 \pi k L} g\left(\frac{t}{t_{s}} \frac{r}{L}, B H E \text { coordinates }\right)
$$

226 Where $T_{\text {ave }, r}$ is the temperature at the distance $r$ from the borehole averaged over the BHE length, $Q(t)$ is the step heat pulse 227 acting on the borehole, $\mathrm{k}$ is the thermal conductivity of the ground, $\mathrm{L}$ is the BHE length, $r$ is the radial distance from the BHE 228 centre, $t$ is time, $g$ is the g-function.

\section{2.4.2 Temporal superposition}

230 The g-functions by definition enable the calculation of the temperature response of a BHE only to a step heat pulse. In 231 practice, the heating demand varies over time, which makes it necessary to convert the time varying profile into the temporal 232 superposition of several step heat pulses. This is done using (4) and the detailed algorithmic flow is described in [41].

$$
T_{b}\left(t_{n}\right)-T_{g r, \infty}=\sum_{i=1}^{n} \frac{\left(Q_{i}-Q_{i-1}\right)}{2 \pi k L} g\left(\frac{t_{n}-t_{i-1}}{t_{s}}, \frac{r_{b}}{L}\right)
$$

234 Where $Q_{i}$ is the heat pulse for time step $t_{i} \forall \mathrm{i} \in(1, \mathrm{n}) ; \mathrm{n}$ is the total number of heat pulses; $r_{b}$ is the radius of the BHE boundary 235 wall and $T_{b}$ is the temperature at the BHE boundary wall. This calculation is performed for each of the time instant $\left(t_{n}\right)$ to create 236 a smooth hourly evolution curve of $T_{b}$. 
237 To improve computational times for simulation of long-term BHE operation, aggregation of loads is carried out. Several 238 approaches have been used in the literature for the aggregation of loads including the multiple load aggregation algorithm (MLAA) 239 [42] and the simple algorithm proposed by Yavuzturk and Spitler [41]. The latter is employed in this study. The conceptual basis 240 of this algorithm is to lump the loads that have occurred more than a given time ago into blocks of a given size. The given time is 241 specified as an input parameter called the minimum hourly history period (MHHP), and the given size is specified as the aggregated 242 load block (ALB). A value of $192 \mathrm{~h}$ for the MHHP is sufficient to keep the error in final temperatures due to aggregation within $243 \pm 0.05^{\circ} \mathrm{C}$ [41]. In this study, conservative value of 500h for MHHP and additionally a value of 730h for ALB has been used.

\section{2.4.3 Spatial superposition}

245 The thermal interference between BHEs is accounted for using the superposition principle [38, 39]. It states that thermal 246 response of given BHE is equal to the superposition of the respective thermal responses of neighbouring BHEs, each calculated at 247 the centre of the given BHE. The superposition principle can be written in terms of temperature response as described by (5).

$$
T_{a v e, r_{b}, i}=\left.T_{a v e, r_{b}, i}\right|_{g_{i}}\left(r=r_{b^{\prime}}, t\right), Q_{i}+\left.\sum_{\forall j \neq i} T_{a v e, r_{j i} j^{j}}\right|_{g_{j}}\left(r=r_{j i}, t\right), Q_{j}
$$

250 Where $T_{i}$ is the net temperature response of the $\mathrm{i}^{\text {th }}$ BHE due to itself and neighbouring BHEs. $\left.T_{i}\right|_{g_{i}}\left(r=r_{b^{\prime}} t\right), Q_{i}$ is the temperature 251 response of the ith BHE calculated at $r=r_{b}$ and heat pulse $\left.Q_{i} \cdot T_{j}\right|_{g_{j}}\left(r=r_{j i} t\right), Q_{j}$ is the temperature response of the $\mathrm{j}^{\text {th }}$ neighbour 252 calculated at a distance $r=r_{j i}$ and heat pulse $Q_{j} . r_{j i}$ is the distance from the $\mathrm{j}^{\text {th }}$ BHE to the $\mathrm{i}^{\text {th }}$ BHE.

\section{2.4.4 Mean fluid temperature (MFT)}

254 The MFT can be calculated by assuming steady state heat transfer between the heat carrier fluid in the u-pipe and the borehole 255 boundary wall. The borehole is filled with grout material that acts as a thermal resistance between the u-pipe containing the thermal 256 carrier fluid and the surrounding ground. For the sake of simplicity, a constant value 0.17 is assumed for the grout thermal 257 resistance $R_{b}$. MFT is calculated using (6).

$$
T_{m f}(t)=T_{b}(t)-\frac{Q(t) R_{b}}{L}
$$

259 Where $T_{m f}(t)$, is the MFT in the u-pipe, $Q(t)$ is the net thermal energy exchanged from the given BHE both as functions of time 260 and $L$ is the length of the given BHE. The MFT in all BHEs is restricted above $-1.5^{\circ} \mathrm{C}$ that could result in a part of the heat demand 261 being unmet. Since there are no upper limits to the MFT, the cooling demand is always met.

\section{2.5 Geothermal Energy Potential (GEP)}

263 The heating demand of the buildings that is met by the BHEs maintaining the TMF above the restrictive threshold of $-1.5^{\circ} \mathrm{C}$ 264 is aggregated for the whole year to calculate the GEP. 


\section{3. Case Study}

\section{3.1 Description}

267

In order to illustrate the methodology developed in this study, a neighbourhood called Altstetten, in Zurich, Switzerland is

268 chosen as a case study. It consists of 170 buildings confined within 135 parcels spanning an area of $108,000 \mathrm{~m}^{2}$. All the buildings

269 are residential with a mix of detached single-family houses, semi-detached family houses, terraced/row houses and small medium

270 and large multi-family apartments as shown in Figure 5. The use of GSHPs is suggested by the city of Zurich in their energy plan

271 for 2050 as centralized solutions such as district heating are not ideal due to its low energy density [43]. This is illustrated by figure

272 6. The area spanned by the case study is divided into two soil type zones, first of which covers almost $85 \%$ of the area consists of

273 silt and clay (zone1), and the second, which consists of loamy gravel (zone2).

274

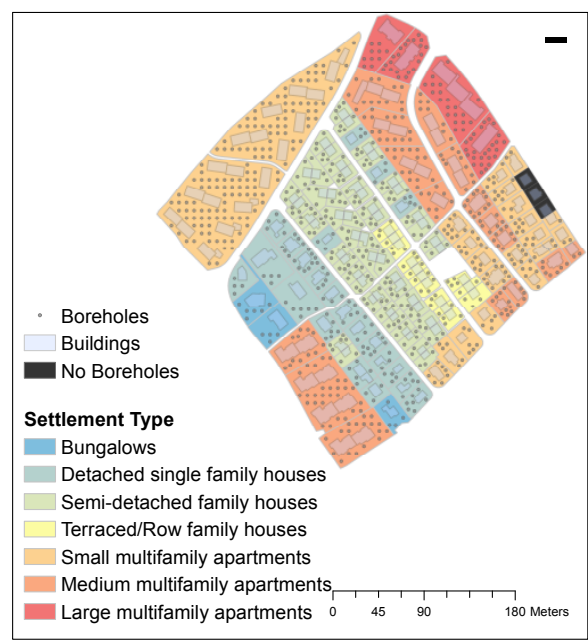

Figure 5: Settlement types within the case study

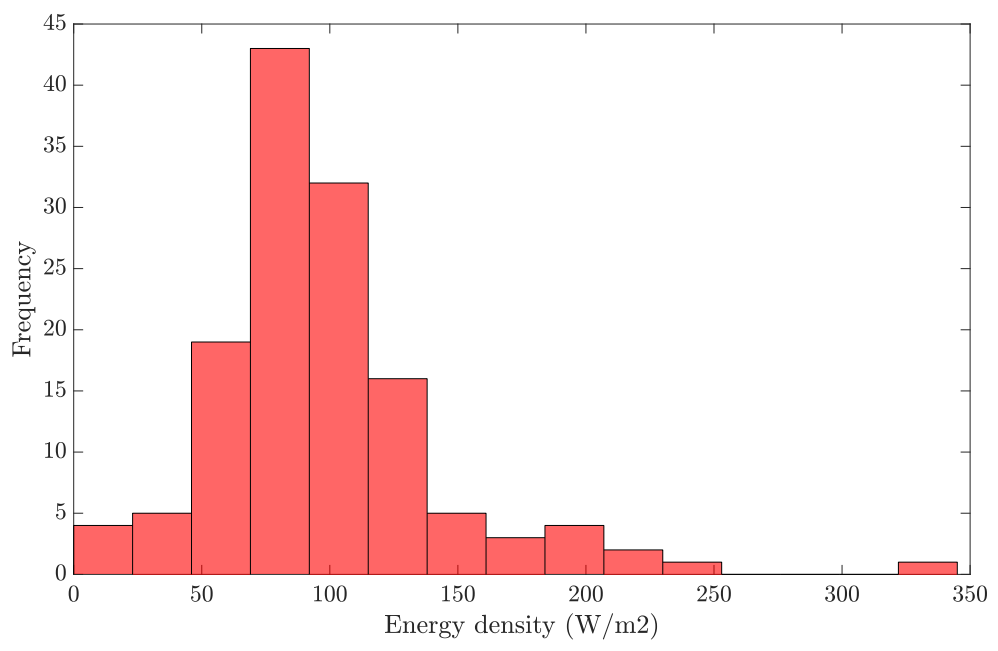

Figure 6: Distribution of energy density of parcels within the case study

\section{3.2 Input parameters}

276 Table 2 lists the input parameters for the case study with their respective values, units and the source for their values.

277 Table 2: Input parameters for the case study

\begin{tabular}{llll}
\hline Parameter & Unit & Value & Source \\
\hline Borehole separation & $\mathrm{m}$ & 7.5 & Chosen value recommended by SIA [14 \\
\hline $\begin{array}{l}\text { Buffer distance from building/parcel } \\
\text { boundaries }\end{array}$ & $\mathrm{m}$ & 3 & Chosen value \\
\hline Design MFT & ${ }^{\circ} \mathrm{C}$ & -1.5 & SIA design standard [14] \\
\hline Coefficient of performance (COP) & - & 4 & Chosen value \\
\hline Energy Efficiency Ratio (EER) & - & 4.5 & Chosen value \\
\hline Borehole thermal resistance & $\mathrm{m} \mathrm{K} / \mathrm{W}$ & 0.17 & ASHRAE Handbook [34] \\
\hline Borehole diameter & $\mathrm{mm}$ & 125 & ASHRAE Handbook [34] \\
\hline Pipe diameter & $\mathrm{mm}$ & 32 & ASHRAE Handbook [34] \\
\hline Soil thermal conductivity & $\mathrm{W} / \mathrm{m} \mathrm{K}$ & 1.7 (zone1), 1.4 (zone2) & SIA design standard [14] \\
\hline Soil thermal diffusivity & $\mathrm{m} 2 /$ day & 0.063 (zone1), 0.052(zone2) & SIA design standard [14] \\
\hline BHE system lifetime & Years & 50 & Chosen value \\
\hline ALB & Hours & 730 & Chosen value \\
\hline MHHP & Hours & 500 & Chosen value \\
\hline
\end{tabular}




\section{4. Results and Discussion}

\subsection{Heat energy demand}

281 The spatial distribution of the annual heat demand $\left(\mathrm{kWh} / \mathrm{m}^{2} / \mathrm{a}\right)$ which includes space heating and DHW, calculated per parcel,

282 is shown in Figure 7a. The peak heat demand is shown in Figure 7b. The annual heat demand ranges from 53 to $330 \mathrm{~kW} / \mathrm{m}^{2} / \mathrm{a}$. It 283 is the highest for parcels with relatively old single-family detached, semi/detached and row houses and the lowest for parcels 284 containing newly built multifamily houses. The peak heat demand ranges from 13 to $410 \mathrm{~kW}$. It is higher for the larger parcels 285 with multifamily houses and lower for the smaller parcels consisting of single-family houses.

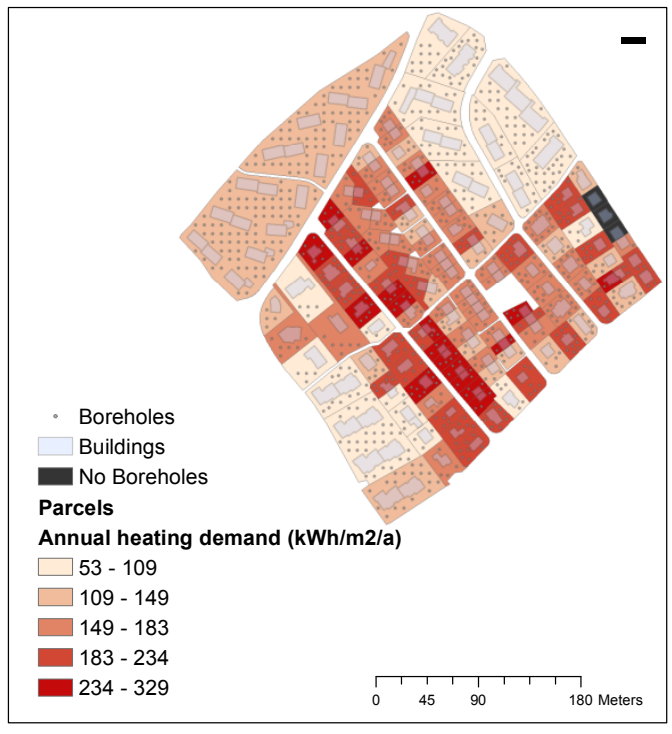

(a) Annual heating demand $\left(\mathrm{kWh} / \mathrm{m}^{2} / \mathrm{a}\right)$

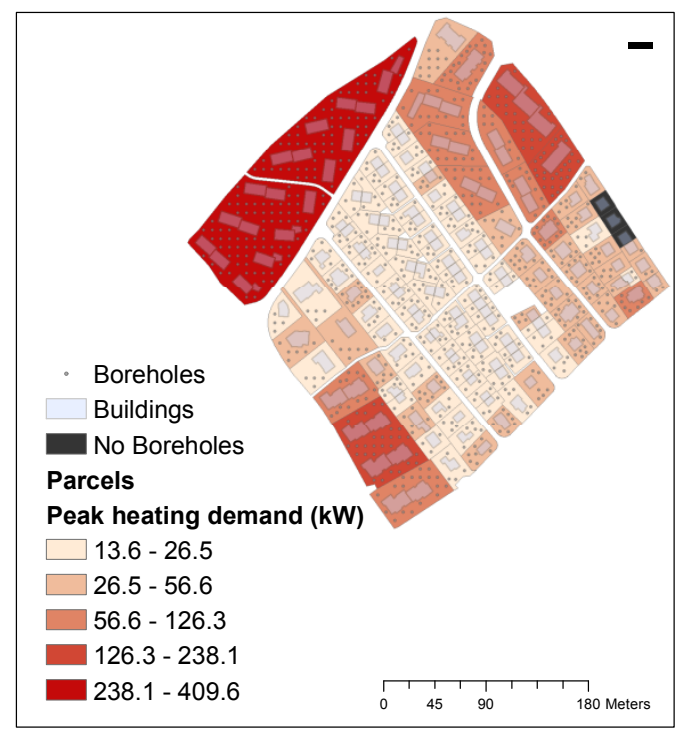

(b) Peak heating demand $(\mathrm{kW})$

Figure 7: Heating demand for DHW and space heating

287 Additionally, the observed departure from the above-mentioned general trends and other smaller variation between distinct 288 buildings can be attributed to factors such as variations in occupancy profile, thermostat usage, glazing ratios, attachment to other 289 buildings, and shading from neighbouring buildings.

\section{4.2 BHE design}

291 Figure 8a shows average BHE design length $(\mathrm{m})$ per parcel taking into account the drilling constraints. The BHE length 292 ranges from $180 \mathrm{~m}$ to $220 \mathrm{~m}$ that are typical for such systems. A spatial correlation of the BHE length with the maximum allowed 293 drilling depth is observed. This is due to the under sizing of BHEs as the result of the presence of drilling depth restrictions. The 294 required length for supplying the heat energy demand for almost all parcels is greater than the maximum drilling depth, causing 295 the BHEs to be under sized. This is illustrated in Figure $8 \mathrm{~b}$ that depicts the BHE length as a percentage of total required length. It 296 is observed that the BHE design length is as low as $15 \%$ of the required length leaving the BHE $85 \%$ under sized. There are three 
297 parcels highlighted in Figure 8b (black) where no boreholes can fit due to spatial restrictions such as parcel boundary being too 298 close to the building boundary.

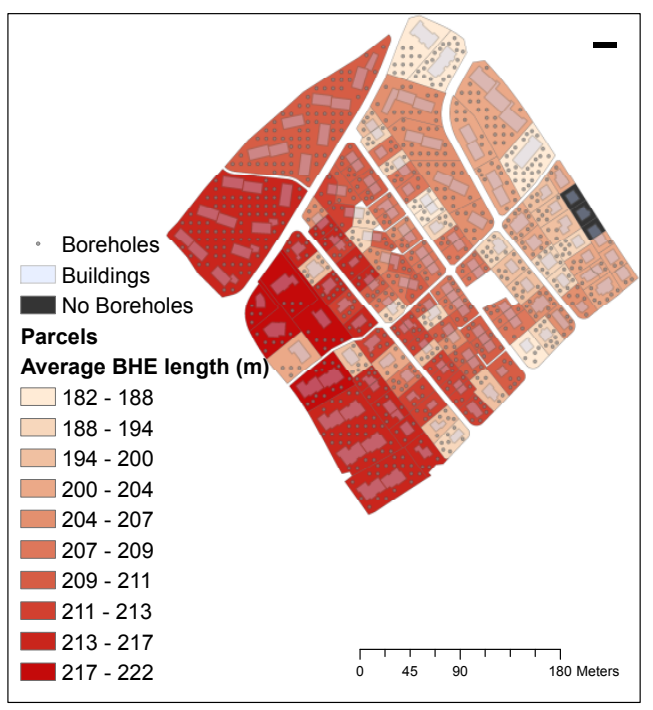

(a) Average BHE length per parcel (m)

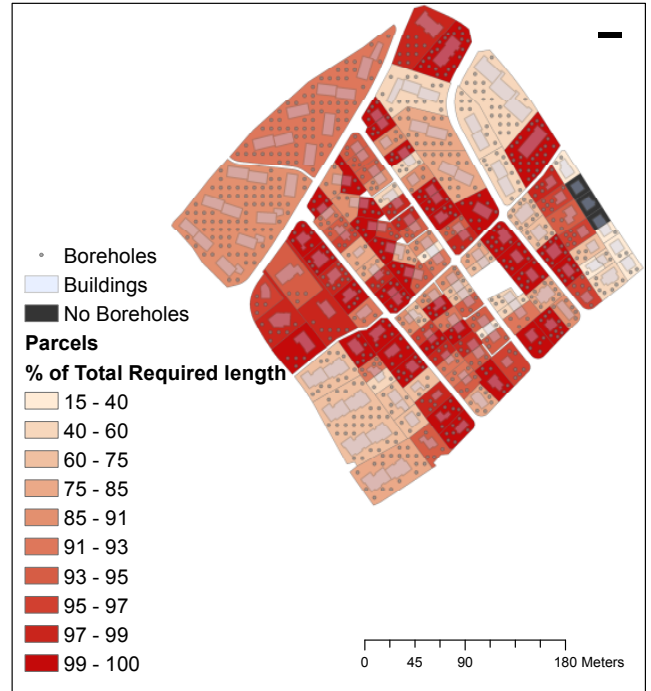

(b) Percentage of total required length

Figure 8: BHE design lengths

\section{4.3 BHE Operation}

301 The MFT is restricted above a threshold of $-1.5^{\circ} \mathrm{C}$. As it drops below this given threshold, the operation of the BHE is 302 interrupted and heating demand is unmet. This is illustrated in Figure 9 that shows the hourly met and unmet heat demand of a 303 single example BHE in parallel with the hourly evolution of the MFT within the BHE for first year of operation. It is clear that 304 some of the heating demand remains unmet by the BHE system hence the need for auxiliary heating technologies is necessitated. 305 This will help in achieving security of heat supply for the building. This unmet heating demand can be attributed to insufficient 306 length of the BHE and/or the simultaneous heat extraction of multiple BHE systems in close vicinity.
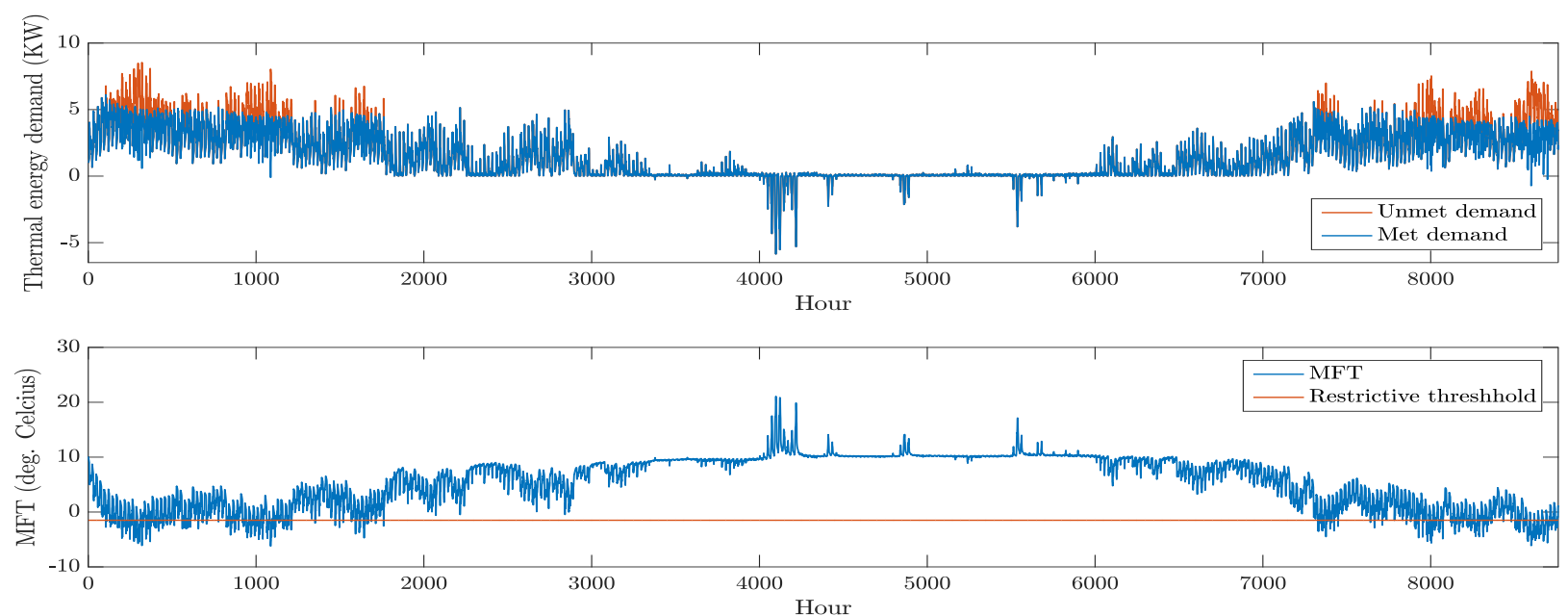

308 Figure 9: Hourly heating/cooling demand and MFT variation for a single example BHE in the 1st year of operation 
309 Figure 10a shows the maximum number of hours of unmet heat demand per parcel in the $1^{\text {st }}$ year of operation. A majority of 310 parcels have minor interruption of the BHE operation within the range of 0-25 unmet hours annually and some have major 311 interruptions going upto 2500 to 4000 unmet hours. The interruption of BHE operation does not necessarily imply the total failure 312 in the supply of the heat demand to the building. In case of interruption, the unmet heat demand can be met through auxilliary 313 technologies such as a gas boiler. The unmet heat demand (percentage of total) for each parcel is shown in Figure 10b. Its highest 314 value is within $10 \%$ of the total heat energy demand. However, these results are only the first year of operation. The long-term 315 operation of the BHEs increases the percentage of unmet heat demand over time. This long term effect is illustrated by Figure $31611 \mathrm{a}, \mathrm{b}$ as described below.

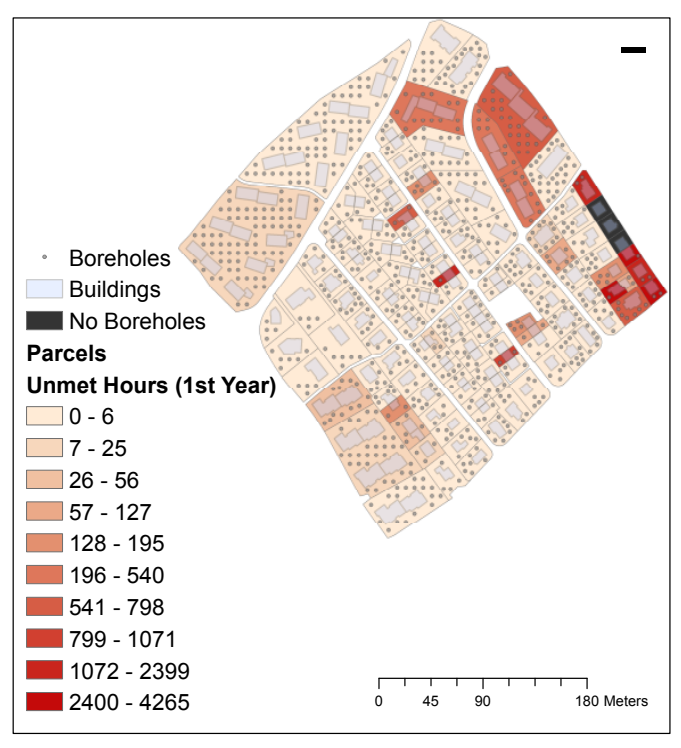

(a) Hours of unmet demand per parcel

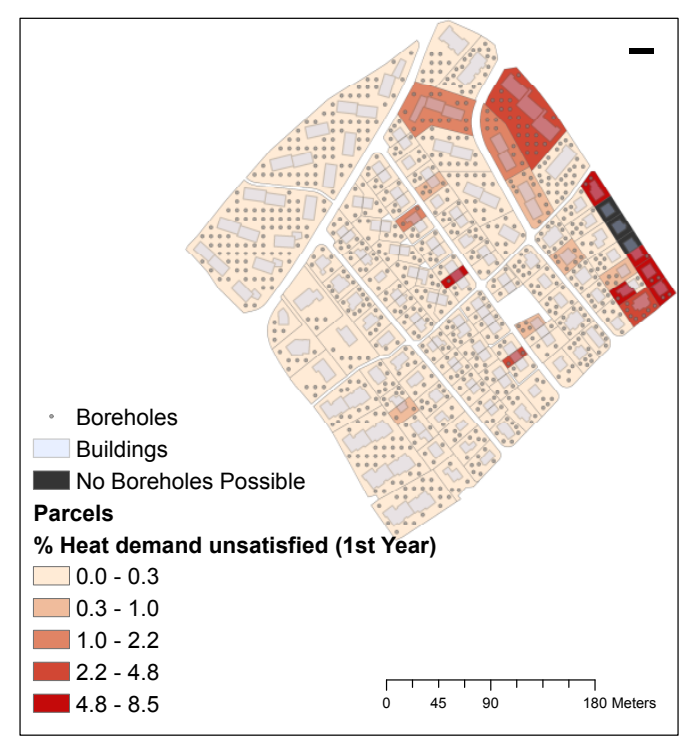

(b) Percentage heat demand unmet

Figure 10: BHE interruption of operation in the first year

\section{4.4 Long term operation}

319 Figure 11a shows the distribution of the number of unmet hours for each parcel (represented by dots) over 10 simulated years 320 of operation. It is observed that the mean number of unmet hours increases at a slow rate up until the $5^{\text {th }}$ year of operation followed 321 by a steep increase in the later years of operation. The spread of values also increases with time indicating the time dependent 322 behaviour of each BHE within each parcel depending upon its specific heating demand, spatial location, influence from neighbours 323 etc. There are several parcels which, starting from the first year of operation itself exhibit a high number of unmet hours. These 324 unmet hours in most cases, occur during the heating season and hence any value above a few hundred hours is a serious cause for 325 concern in the viability of such systems. This can be solved through interventions in the building's energy supply system such as 326 using gas boilers for supplying peak heat demand and solar thermal collectors for seasonal regeneration of the ground. Demand 327 side interventions such as retrofit of the building envelope can reduce the heat demand of the building thereby reducing the load 328 on the BHEs. Figure $11 \mathrm{~b}$ similarly shows the distribution of unmet heating demand relative to the total heating demand for each 
329 parcel. Similar trends are observed and it is clear that on an average the amount of unmet heating demand is almost zero up until 330 the $7^{\text {th }}$ year of operation. There are parcels which require heat to be put into ground to maintain adequate temperatures in the BHE 331 for smooth operation (values $>1$ ) starting as early as the first year of operation. The short and long-term variation in the MFT for 332 an example BHE are shown in Figure 12. Cases with and without restriction of the MFT above $-1.5^{\circ} \mathrm{C}$ are displayed. A BHE in 333 which the long-term effects are more pronounced is selected. It indicates a declining trend over time as heat is continuously 334 extracted each year. This causes the number of unmet hours and unmet heat demand to increase with each year of operation. The 335 unmet heat demand can be reduced or eliminated if the net annual heat imbalance is close or equal to zero. Therefore, in areas 336 where heat extraction during winter is predominant, excess heat can be added to the ground during the summer season for instance, 337 using solar thermal systems.

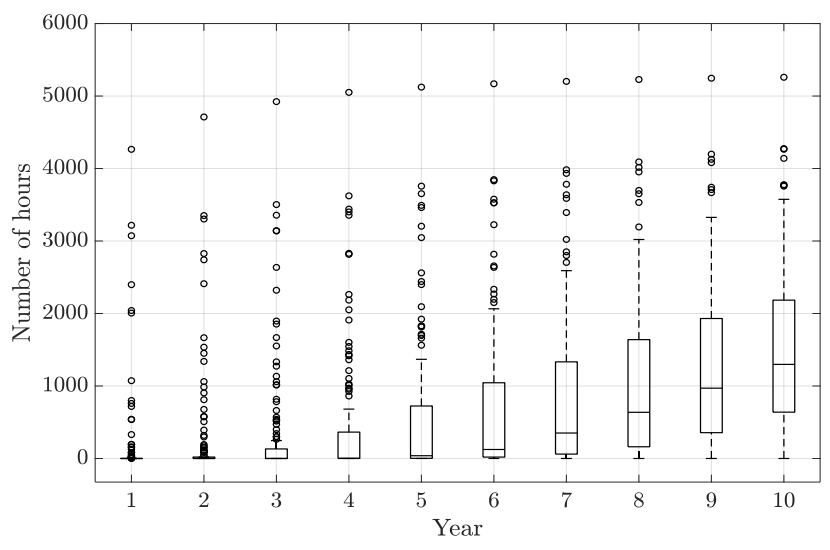

(a)

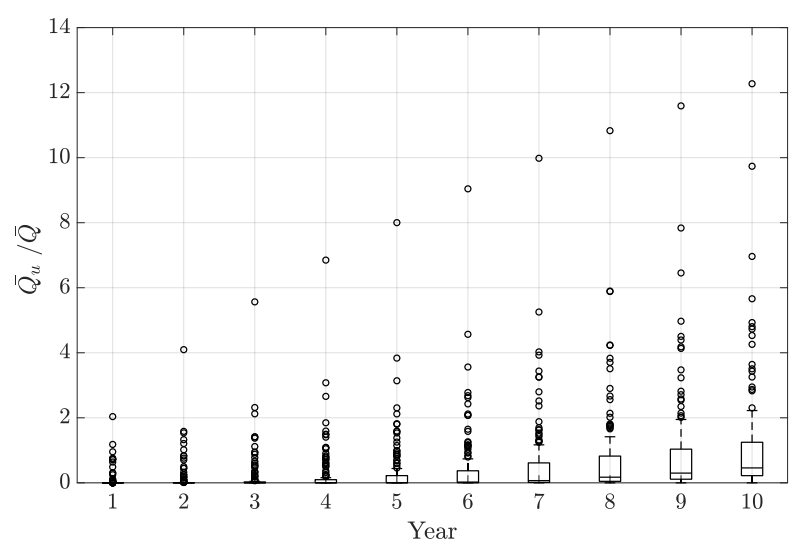

(b)

Figure 11: Distribution of hours of (a) interrupted operation and (b) heat demand for all parcels over 10

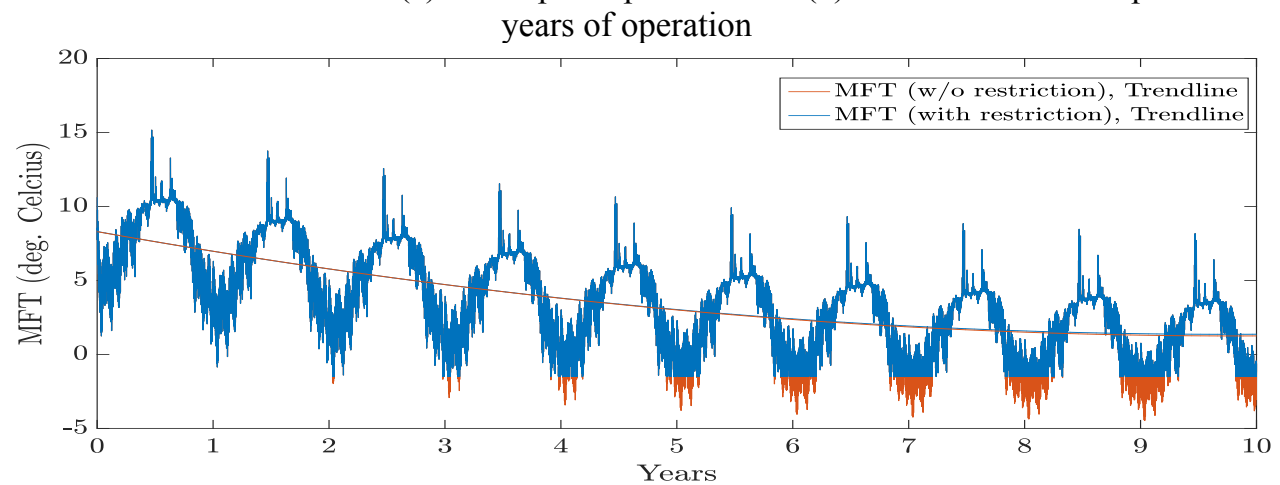

Figure 12: Long-term variation and trends in the MFT for an example BHE

\subsection{Impact of thermal interference}

342 To emphasize the impact of thermal interference between BHEs on each other's thermal performance and thereby the GEP, 343 a comparative analysis is performed. The results of this study are compared to a reference case that assumes no thermal interference 344 between BHEs. Figure 13 shows the long-term variation and trends in the MFT for the same example BHE now for the reference 345 case. The MFT with and without restriction above $-1.5^{\circ} \mathrm{C}$ and hence the trend lines follow the same path since the MFT does not 
346 cross this threshhold. The MFT exhibits a very small overall cooling trend but it is less pronounced as observed in Figure 12. The 347 MFT does not cross the restrictive threshold providing uninterrupted BHE operation. This indicates that the BHEs appear to operate 348 without any interruption and without any significant overall cooling of the ground over long period.

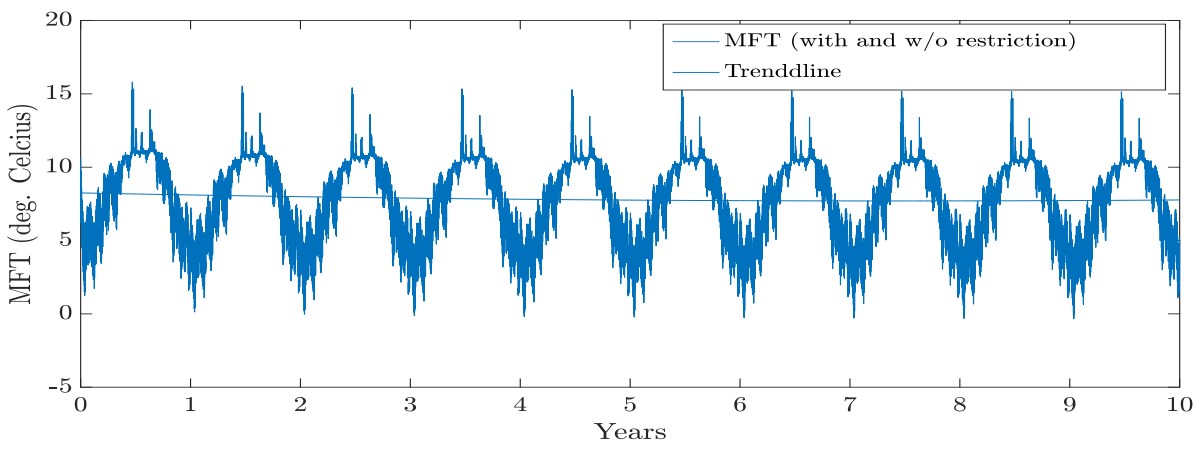

350 Figure 13: Long-term variation and trends in the MFT for the same example BHE for the reference case (no interference)

351 The results of the unmet heat demand for the reference case are described in Figure 14. On an average, most of the parcels have 352 almost zero number of hours of interrupted operation even up until the $10^{\text {th }}$ year of operation. Similarly, the ratio of unmet heat 353 demand to the total heat demand for most parcels remain close to zero also up until the $10^{\text {th }}$ year of operation. This indicates that 354 for most parcels a long term uninterrupted operation is possible if thermal interference between BHEs did not exist. Although there 355 are some parcels that are outliers to this effect that can be attributed to the insufficient lengths of their BHEs. Furthermore, the 356 magnitude by which they lie outside is lower if compared to Figure 11. This indicates that the overall GEP is overestimated if 357 thermal interference between BHEs is not considered in the modelling proces. It can be concluded through this comparative 358 analysis that for an accurate calculation of the long term GEP for an urban area, thermal interference between BHEs should be 359 taken into account in the model.

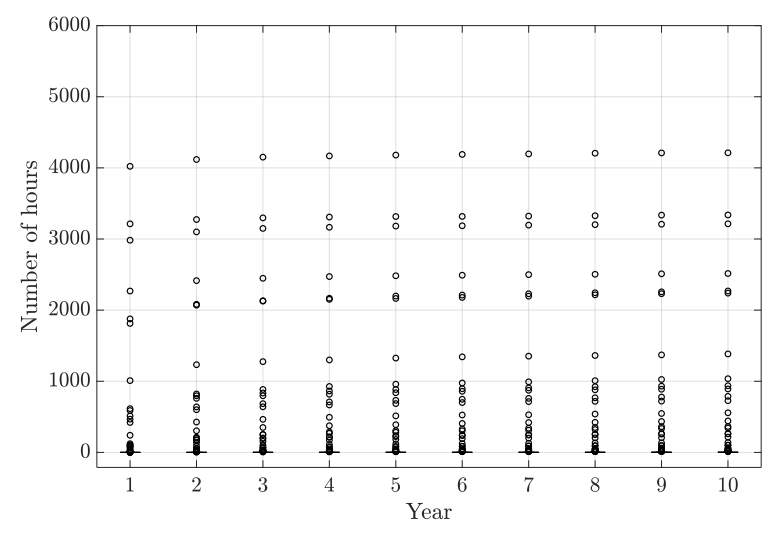

(a)

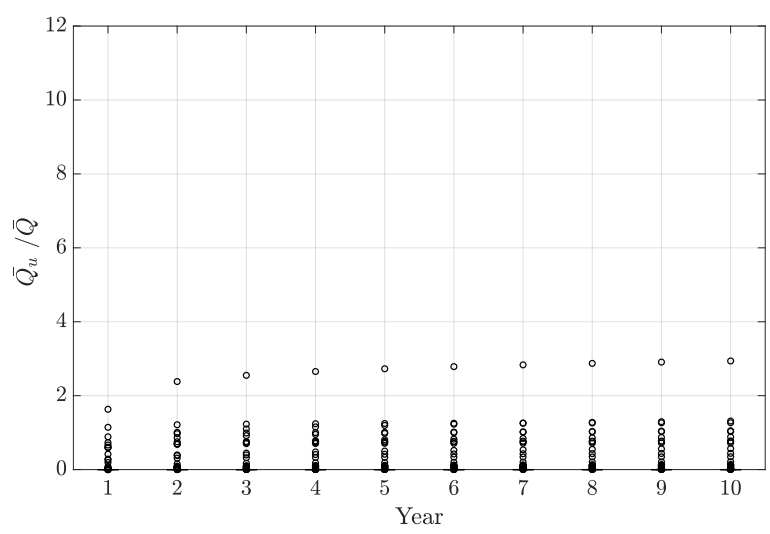

(b)

Figure 14: Distribution of hours of interrupted operation (a) and heat demand (b) for parcels over 10 years of operation for reference case (no interference) 


\section{4.6 Geothermal Energy Potential}

362 Figure 15 shows the evolution of of the net GEP normalized by the parcel area (in W/m2) for all the parcels for 10 years of 363 operation. On an average the trends show that there is a decrease in the net GEP for majority of the parcels over time which can 364 be attributed to ground cooling. Parcels with relatively high energy density exhibit a sharper decline in the net GEP whereas the 365 parcels with low energy density exhibit a slow decline. This is due to the limited heat capacity of the ground and overuse. Auxilliary 366 systems like gas boiler, solar thermal collectors can be used to limit the overuse of the ground. This can help maintain the 367 sustainabilits of the GEP.

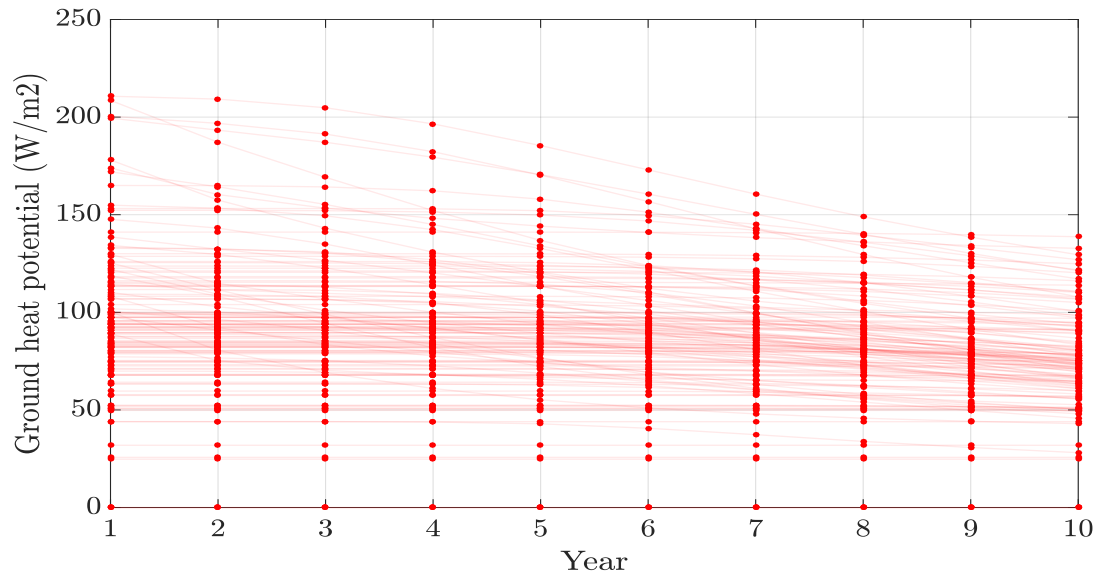

Figure 15: GEP per unit parcel area for all parcel over 10 years of operation

\section{5. Conclusion}

371 In this study, a GIS based methodology is developed to estimate the sustainable GEP in an urban area where multiple 372 buildings are equipped with BHEs in conjunction with GSHPs. The developed methodology addresses the practical constraints in 373 the design and operation of GSHPs and their effects on the net available GEP and its sustainability over longer periods. A GIS 374 based workflow is developed to position and size the BHEs taking into account drilling depth restrictions and spatial variation of 375 soil type. Thermal interference between BHEs is also accounted for and its effects of the net available GEP are studied. This 376 method is subsequently applied to an urban neighbourhood called Altstetten in Zurich, Switzerland as a case study. The results 377 indicate that due to the limitations in the drilling depths in urban areas, the BHEs are undersized limiting the amount of thermal 378 energy that can be exchanged with the ground. This necessitates the evaluation of the BHEs operational performance that affects 379 the net GEP. The BHEs in the entire urban area are operating simultaneously and have a significant impact on each other's thermal 380 performance. This is illustrated through comparing the developed methodology to a reference case that assumes no thermal 381 interference between BHEs. It has been shown that the GEP is overestimated if thermal interference is not taken into account. 382 There are several hours in the heating season when the heat pump operation is interrupted necessitating the use of backup auxiliary 383 technologies to fulfil the unmet heat demand. The magnitude of the unmet demand depends on how long the system has been 
384 operating and exchanging heat with the ground. The results also show that the GEP decreases over longer periods of heat extraction.

385 This can be addressed through the thermal regeneration of the ground. Technologies such as solar thermal collectors can be used 386 to recharge the ground during the summer season, boilers based on natural gas or oil may well be used. The design of the technical 387 systems to recharge the ground and simultaneously provide a secure thermal energy supply to the buildings is a matter of future 388 scientific enquiry.

\section{Acknowledgements}

390 This research in the present contribution was funded in part by SCCER "Future Energy Efficient Buildings and Districts" 391 (CTI.1155000149).

\section{References}

393 [1] Europe 2020: A strategy for smart, sustainable and inclusive growth, Brussels, 2010. doi:10.1007/s13398-014-0173-7.2.

394 [2] Energy Roadmap 2050, Brussels, 2011.

395 [3] International Energy Agency, Transition to Sustainable Buildings - Strategies and opportunities to 2050, Paris, 2013. 396 doi:10.1787/9789264202955-en.

397 [4] J.O. Lewis, S.N. Hógáin, A. Borghi, Building Energy Efficiency in European Cities, Paris, 2013. 398 http://urbact.eu/fileadmin/general_library/19765_Urbact_WS6_ENERGY_low_FINAL.pdf.

399 [5] Directive 2010/31/EU of the European Parliament and of the Council of 19 May 2010 on the energy performance of buildings 400 (recast), Brussels, 2010. doi:doi:10.3000/17252555.L_2010.153.eng.

401 [6] C. Karytsas, Current state of the art of geothermal heat pumps as applied to buildings, Adv. Build. Energy Res. 6 (2012) 119 402 140. doi:10.1080/17512549.2012.672004.

403 [7] I. Sarbu, C. Sebarchievici, General review of ground-source heat pump systems for heating and cooling of buildings, Energy 404 Build. 70 (2014) 441-454. doi:10.1016/j.enbuild.2013.11.068.

405 [8] G. Florides, S. Kalogirou, Ground heat exchangers-A review of systems, models and applications, Renew. Energy. 32 (2007) 406 2461-2478. doi:10.1016/j.renene.2006.12.014.

407 [9] K. Schiel, O. Baume, G. Caruso, U. Leopold, GIS-based modelling of shallow geothermal energy potential for CO2 emission 408 mitigation in urban areas, Renew. Energy. 86 (2016) 1023-1036. doi:10.1016/j.renene.2015.09.017.

409 [10] R.H.D. Rawlings, J.R. Sykulski, Ground source heat pumps: A technology review, Build. Serv. Eng. Res. Technol. 20 (1999) 410 119-129. doi:10.1177/014362449902000304.

411 [11] S. Haehnlein, P. Bayer, P. Blum, International legal status of the use of shallow geothermal energy, Renew. Sustain. Energy 412 Rev. 14 (2010) 2611-2625. doi:10.1016/j.rser.2010.07.069.

413 [12] A. Amt fur Abfall, Wasser, Energie und Luft, Energienutzung aus Untergrund und Grundwasser, Zurich, 2010. 
414 [13] E. Bertram, Heat Pump Systems with Vertical Ground Heat Exchanger and Uncovered Solar Thermal Collectors, MV-Verlag, 4152015.

416 [14] Schweizerischer Ingenieur- und Architektenverein, Erdwärmesonden. SIA 384/6:2010, Zurich, 2010.

417 [15] A. Galgaro, E. Di Sipio, G. Teza, E. Destro, M. De Carli, S. Chiesa, A. Zarrella, G. Emmi, A. Manzella, Empirical modeling 418 of maps of geo-exchange potential for shallow geothermal energy at regional scale, Geothermics. 57 (2015) $173-184$. 419 doi:10.1016/j.geothermics.2015.06.017.

420 [16] A. Gemelli, A. Mancini, S. Longhi, GIS-based energy-economic model of low temperature geothermal resources: A case 421 study in the Italian Marche region, Renew. Energy. 36 (2011) 2474-2483. doi:10.1016/j.renene.2011.02.014.

422 [17] J. Ondreka, M.I. Ruesgen, I. Stober, K. Czurda, GIS-supported mapping of shallow geothermal potential of representative 423 areas in south-western Germany-Possibilities and limitations, Renew. Energy. 32 (2007) 2186-2200. 424 doi:10.1016/j.renene.2006.11.009.

425 [18] M. Muñoz, P. Garat, V. Flores-Aqueveque, G. Vargas, S. Rebolledo, S. Sepúlveda, L. Daniele, D. Morata, M.Á. Parada, 426 Estimating low-enthalpy geothermal energy potential for district heating in Santiago basin-Chile (33.5 ${ }^{\circ}$ S), Renew. Energy. 76 427 (2015) 186-195. doi:10.1016/j.renene.2014.11.019.

428 [19] A. Casasso, R. Sethi, G.POT: A quantitative method for the assessment and mapping of the shallow geothermal potential, 429 Energy. 106 (2016) 765-773. doi:10.1016/j.energy.2016.03.091.

430 [20] Y. Zhang, R. Choudhary, K. Soga, Influence of GSHP system design parameters on the geothermal application capacity and 431 electricity consumption at city-scale for Westminster, London, Energy Build. 106 (2015) 3-12. doi:10.1016/j.enbuild.2015.07.065. 432 [21] A. García-Gil, E. Vázquez-Suñe, M.M. Alcaraz, A.S. Juan, J.Á. Sánchez-Navarro, M. Montlleó, G. Rodríguez, J. Lao, GIS433 supported mapping of low-temperature geothermal potential taking groundwater flow into account, Renew. Energy. 77 (2015) 434 268-278. doi:10.1016/j.renene.2014.11.096.

435 [22] P. Blum, G. Campillo, T. Kölbel, Techno-economic and spatial analysis of vertical ground source heat pump systems in 436 Germany, Energy. 36 (2011) 3002-3011. doi:10.1016/j.energy.2011.02.044.

437 [23] P. Blum, G. Campillo, W. Münch, T. Kölbel, CO2 savings of ground source heat pump systems - A regional analysis, Renew. 438 Energy. 35 (2010) 122-127. doi:10.1016/j.renene.2009.03.034.

439 [24] P. Eskilson, G. Hellstrom, J. Claesson, T. Blomberg, B. Sanner, Earth Energy Designer (EED), Lund, Sweden, 2000. 440 http://www.buildingphysics.com/manuals/eed.pdf.

441 [25] A. Casasso, R. Sethi, Assessment and mapping of the shallow geothermal potential in the province of Cuneo (Piedmont, NW 442 Italy), Renew. Energy. (2016). doi:10.1016/j.renene.2016.10.045.

443 [26] Swiss Federal Office of Topography, swissBUILDINGS3D, Zurich, 2013. 
444 [27]Bundesamt für Statistik, Gebäude- und Wohnungsregister, Zurich, 2013.

445 https://www.bfs.admin.ch/bfs/de/home/register/gebaeude-wohnungsregister.html.

446 [28] Meteonorm, Meteotest, Bern, Switzerland, 2014.

447 [29] Amt für Raumentwicklung, Bodenbedeckung, Zurich, 2015. www.are.zh.ch.

448 [30] Federal Office of The Environment, Hydrogeological Atlas of Switzerland, Zurich, n.d.

449 [31] Amt für Raumentwicklung, Wärmenutzung, Zurich, 2015. www.are.zh.ch.

450 [32] D. Wang, K. Orehounig, J. Carmeliet, Dynamic building energy demand modelling at urban scale for the case of Switzerland, 451 in: CLIMA 2016 - Proc. 12th REHVA World Congr., 2016.

452 [33] D. Crawley, C. Pedersen, EnergyPlus: energy simulation program, ASHRAE J. 42 (2000) 49-56.

453 [34] K. Kavanaugh, Steve; Rafferty, Geothermal Heating and Cooling, Design of Ground-Source Heat Pump Systems, ASHRAE, 4542014.

455 [35] M.A. Bernier, Closed-Loop Ground-Coupled Heat Pump Systems Ground Heat Exchanger Length, ASHRAE J. (2006).

456 [36] P. Eskilson, Thermal Analysis of Heat Extraction Boreholes, Response. (1987) 222.

457 [37] H.Y. Zeng, N.R. Diao, Z.H. Fang, A finite line-source model for boreholes in geothermal heat exchangers, Heat Transf. 458 Asian Res. 31 (2002) 558-567. doi:10.1002/htj.10057.

459 [38] L. Lamarche, B. Beauchamp, A new contribution to the finite line-source model for geothermal boreholes, Energy Build. 39 460 (2007) 188-198. doi:10.1016/j.enbuild.2006.06.003.

461 [39] L. Lamarche, A fast algorithm for the hourly simulations of ground-source heat pumps using arbitrary response factors, 462 Renew. Energy. 34 (2009) 2252-2258. doi:10.1016/j.renene.2009.02.010.

463 [40] A.D. Chiasson, Geothermal Heat Pump and Heat Engine Systems: Theory And Practice Wiley-ASME Press Series, John 464 Wiley \& Sons, 2016, 2016.

465 [41] C. Yavuzturk, A Short Time Step Response Factor Model for Vertical Ground Loop Heat Exchangers, ASHRAE Trans. 105 466 (1999) 475-485.

467 [42] M. Bernier, P. Pinel, R. Labib, R. Paillot, A Multiple Load Aggregation Algorithm for Annual Hourly Simulations of GCHP 468 Systems, HVAC\&R Res. 10 (2004) 471-487. doi:10.1080/10789669.2004.10391115.

469 [43] M. Jakob, K. Flurry, N. Gross, G. Martius, B. Sunarjo, Kurzbericht Konzept Energieversorgung 2050: Szenarien für eine 470 2000-Watt-kompatible Wärme-versorgung für die Stadt Zürich, 2014.

471 